Boston University School of Law

Scholarly Commons at Boston University School of Law

Faculty Scholarship

1982

The Emerging Stowaway: Patients' Rights in the 1980s

George J. Annas

Follow this and additional works at: https://scholarship.law.bu.edu/faculty_scholarship

Part of the Health Law and Policy Commons 


\title{
The Emerging Stowaway: Patients' Rights in the 1980s
}

\author{
by George J. Annas, J.D., M.P.H.
}

\begin{abstract}
A Narrative of Arthut Gordon Pym of Nantucket, Pym, who has stowed away in the hold of a whaling vessel, believes he has been abandoned and that the hold will be his tomb. He expressed sensations of "extreme horror and dismay," and "the most gloomy imaginings, in which the dreadful deaths of thirst, famine, suffocation, and premature interment, crowded in as the prominent disasters to be encountered."

It is probably uncommon for hospitalized patients to feel as gloomy as Pym. Nevertheless, installed in a strange institution, separated from friends and family, forced to wear a degrading costume, confined to bed, and attended to by a variety of strangers who may or may not keep the patient informed of what they are doing, the average patient is intimidated and disoriented. Such an environment encourages dependence and discourages the assertion of individual rights.

As the physician-director of Boston's Beth Israel Hospital has warned: "today's hospital stands increasingly to become a jungle, whose pathways to the uninitiated are poorly marked and fraught with danger. ..." $\ln$ this jungle the notion that patients have rights that demand respect is often foreign.

The movement for enhanced patients' rights is based on two premises: (1) citizens possess certain rights that are not automatically forfeited by entering into a relationship with a physician or a health care facility; and (2) most physicians and health care facili-
\end{abstract}

Mr. Annas is Associate Professor of Law 8 Medicine at Boston University School of Medicine, Chief of the Health Law Section, Boston University School of Public Health, and Editor-in-Chief Emeritus of LAW, MEDICINE \& HEALTH CARE.

O George J. Annas, J.D., M.P.H. ties fail to recognize these rights, fail to provide for their protection or assertion, and limit their exercise without recourse. $^{2}$

The primary argument against patients' rights is that patients have "needs" and that defining these needs in terms of rights leads to the creation of an unhealthy adversary relationship. ${ }^{3}$ It is not, however, the creation of rights, but the disregard of them, that produces adversaries. When provider and patient work together in an atmosphere of mutual trust and understanding, the articulation of rights can only enhance their relationship.

Many issues, however, cannot be resolved entirely within the providerpatient relationship. Providers not only have formal relationships with their patients but also have relationships with other providers, health care institutions, and numerous governmental agencies. A provider's relationship with these institutions and individuals is often a very complex one, and providers often find themselves confused and therefore submissive in cases where they do not understand the ir own rights or those of their patients.

\section{Rights in Health Care}

In most instances, both the health care provider and the patient will be betrer off if the status of the law regarding both patient and provider rights is understood, and the means of change or challenge well delineated. ${ }^{4}$ I would go even further. An understanding of the law can be as important to the proper care of patients as an understanding of emergency medical procedures or proper drug dosages. But how are rights to be understood, and how does a person know that he or she has a "right" to something?

There is a formidable amount of literature on rights in the archives of phi- losophy and jurisprudence. Rather than review it, let me note briefly the thoughts of two relatively recent entrants who have written with great insight. The first is John Rawls. In expounding his Theory of Justice, ${ }^{5}$ he imagines that a group of men and women come together to form a social contract. These individuals all have ordinary tastes, talents, ambitions, and

The average hospitalized patient is intimidated and disoriented, and in an environment that en. courages dependence and dis. courages the assertion of individual rights.

convictions, but each is temporarily unaware of his own personality and best interests and must agree to the terms of the contract before his awareness of his own identity is restored. The theory postulates that under such circumstances all will agree to two principles: (1) each person shall enjoy the most extensive liberty, compatible with a like liberty for others; and (2) inequalities in wealth and power should exist only where they work to the benefit of the worst-off members of society. One could develop an entire system of patients' rights that rests on these premises. Such a document would be strongly pro-patient since this group is currently the one that generally lacks rights and is always the group that will be viewed as "worstoff" in the health care setting.

A second approach is suggested by the writings of Ronald Dworkin in his book of essays Taking Rights Seriously. ${ }^{6}$ Dworkin notes the great confusion in "rights language," generally created by attributing to it different meanings in different contexts: "In most cases when we say that someone has a right to something, we imply that it would be wrong to interfere with his doing it, 
or at least that some special grounds are needed for justifying an interference." An example is the right to spend one's money the way one pleases. This is, of course, different from saying that the way one spends one's money, e.g., gambling it away, is the "right" thing to do, or that there is nothing "wrong" with it. When we speak of patients' rights, this distinction may be critical to understanding what we are talking about. For example, a woman may have a legal right to have an abortion, but such a decision may still be considered "wrong" by her.

Dworkin argues further that there are some rights that can be said to be fundamental in the sense that the government is bound to recognize and protect them. Such rights, which we often denote as "legal rights," and less frequently as "constitutional rights," are generally spelled out in statutes

Both the health care provider and the patient will be better off if the status of the law regarding both patient and provider rights is understood.

and court decisions. By respecting such rights, the government guarantees to the weakest members of the society that they will not be trampled on by the strongest. In Dworkin's words:

The bulk of the law - that part which defines and implements social, economic, and foreign policy - cannot be neutral. It must state, in its greatest part, the majority's view of the common good. The institution of rights is therefore crucial, because it represents the majority's promise to the minorities that their dignity and equality will be respected. When the divisions a mong the groups are most violent, then this gesture, if law is to work, must be most sincere ... taking individual rights seriously is the one feature that distinguishes law from ordered brutality. ${ }^{?}$

Without going too far afield, one can apply Dworkin's notion directly to health care and note that rights can form a useful means of guaranteeing to defenseless patients that they will be treated with human dignity and respect. While the health care provider of ten has the power to deny certain rights almost at will, he or she does this only at the peril of jeopardizing the integrity of the health care system itself.

\section{The AHA Bill of Rights}

It must strike most as ironic that the first major health care organization to put forward a patients' bill of rights was the American Hospital Association, an organization composed primarily of hospital administrators. One would not expect landlords to pen a bill of rights for tenants, police for suspects, or wardens for prisoners. Nor would one reasonably expect that the hospital administrator's view on rights for patients would be the same as either the patient's or society's. Nevertheless, physicians and nurses should be ashamed that the administrators were out in front on this issue. Even though it leaves much to be desired in terms of completeness, specificity, and enforceability the AHA Bill has tremendous symbolic value in legitimiz ing the notion of rights in the health care institution. ${ }^{8}$ On the other hand fewer than half of all AHA-member hospitals have formally adopted even this bill, and the symbolic victory of the 1970 s is currently under attack.

\section{The Attack on Patient Rights}

Physicians, who perhaps value their own professional autonomy more than any other group, nevertheless devalue it for their own patients. Instead, paternalism is the norm with the majority of physicians who believe that the health and continued life of their patients is much more important than their patients' right to self-determination. This belief system not only leads to conflicts with individual patients about their own care, but also to a general view that patients' rights are a luxury item in medicine rather than a necessity.

A few examples illustrate the point. Two particular rights of patients have recently come under attack in the medical literature: access to medical records and informed consent. In an attack on "record reading," four psy- chiatrists at Peter Bent Brigham Hospital in Boston, Massachusetts, interviewed the 11 out of 2,500 patients at that hospital who, in a one year period, asked to see their medical records. ${ }^{9}$ It is doubtful that anything of general importance about a patient's reactions to reading their charts can be learned from an uncontrolled, non-blind, clinically impressionistic study of those few individuals who, for whatever reason, buck a system which routinely fails to inform them of their right of access to their records. Nonetheless, the authors' conclusion that such patients have a variety of personality defects, usually manifesting themselves in mistrust of and hostility toward the hospital staff, should not be permitted to go uncontested. In a setting where trusting patients are not routincly told of their right to access, it seems reasonable to assume that only the least trusting or most angry will ask to see their records. To locate the source of mistrust in the patient's personality or in the stress of illness and hospitalization is to forget, as Dr. Lipsett perceptively suggests, that "the doctor-patient relationship cannot be understood simply in terms of the patient's side of the equation." 10 Altman, et al., thus fall into what Professor Robert Burt, of Yale Law School, has referred to as "the conceptual trap of attempting to transform two-party relationships, in which mutual self-delineations are inherently confused and intertwined, by conceptually obliterating one party. ..." 1 Thus, it would seem that the ten women who asked to read their charts "to confirm the belief that the staff harbored negative personal attitudes toward them ..." were correct in their belief; the psychiatrists labelled them "of the hysterical type with demanding, histrionic behavior and emotional over-involvement with the staff."

Altman, et. al., also seem unaware of the wide variety of settings in which patients have benefitted from routine record access; and incorrectly assert that there were no strikingly beneficial effects in the two studies they docite. In the first study, for example, two patients expressed their unfounded fear that they had cancer only after their records were reviewed with them, and 
one pregnant patient noted an incor rect $R h$ typing that permitted $R$ hoGam to be administered at the time of delivery. ${ }^{12}$ In the other study they cite, 50 percent of the patients made some factual correction in their records. ${ }^{13}$

In short, the study seems to have been done and published for the primary purpose of proving that the right to access one's medical record is unimportant since it is only exercised by "mentally disturbed" people who are not improved by reading their charts. The study fails to prove this, and even if it succeeded, I would still be unwilling to deprive the other 2,489 patients at that hospital of their right to access in the future.

If we believe in individual freedom and the concept of self-determination, we must give all citizens the right to make their oun decisions and to have access to the same information that is widely available to those making decisions about them. It is as irrelevant in this connection that 2,489 patients at the Brigham did not ask to see their records as it is that more than $200 \mathrm{mil}$ lion Americans never have had to exercise their right to remain silent when arrested. Rights serve us all, whether we exercise them or no:.

The attack on informed consent, which many physicians have long considered a "legal fiction," 14 most recently surfaced in a study designed to prove that informed consent was not an important practice because patients could not remember what they were informed of. ${ }^{15}$ The methodology involved interviewing 200 consecutive cancer patients who had consented to chemotherapy, surgery, or radiation therapy for their cancers within 24 hours after they had signed consent forms. Upon questioning, most could not recall the procedure consented to, its major risks, or the alternatives to it. From this the authors conclude that the process is not working and that informed consent itself is suspect.

While this may seem a reasonable conclusion (although an alternative one is simply that patients have poor recall), it turns out that the authors presumed their major premise. Approximately two-thirds of their sample group ( 66 percent) opted for radiation therapy. That group signed a consent form that said "the procedure, its risks and benefits and alternatives have been explained to me." Maybe they were, but maybe they weren't. The authors did not know, so their entire study was based on a premise that was unsubstantiated. Such a poorly designed study, it seems to me, could only be published if the editors agreed so strongly with the conclusion that they did not even review the methodology.

A perhaps more interesting part of the study asked the patients some general questions about informed consent. The first was "What are consent forms for?" Approximately 80 percent responded: "To protect the physicians' rights." The authors were upset at this response, but the patients, of course, were correct. That is the primary function of forms. If one wants these forms also to protect the patient, three simple steps are necessary: (1) the forms must be complete; (2) they must be in lay language; and (3) the patients must be given a copy of the form and time to think over the information it contains. ${ }^{16}$ The reason none of these is usually done is clear: informed consent is not taken seriously in the hospital setting. It is, like record access, a luxury which is secondary to caring for the medical "needs" of the patient, and besides, it really does not matter anyway because patients cannot remember anything they've been told.

Other significant findings indicate the extent to which patients understand and appreciate the consent process: 80 percent thought the forms were necessary; 76 percent thought they contained just the right amount of information; 84 percent understood all or most of the information; 75 percent thought the explanations given were important; and 90 percent said they would try to remember the information contained on the forms. To me, this suggests that the patients surveyed understood and appreciated the informed consent process much better than the researchers did. While their data is certainly not flawless, one can conclude from it just the opposite of what the researchers did: for almost all patients, informed consent is very important.

Related to this general attack on rights is an attack on the patient popu- lation itself. The notion is that the major problems with the health care delivery system are not problems with providers, but with patients. We eat too much, smoke too much, don't exercise, take too many risks, etc., and so what do we expect when we get sick? Not only must the American health care enterprise deal with a bad class of patients, but now they want some say in what kind of care is provided! As Lewis Thomas has put it in a related vein: this is becoming "folk doctrine about disease. You become ill because of not living right. If you get cancer it is, somehow or other, your own fault. If you didn't cause it by smoking or drinking, or eating the wrong things, it came from allowing yourself to persist with the wrong kind of personality in the wrong environment."17

This attitude would be humorous if it was not so pervasive and did not affect patient care so profoundly. Martha Lear has given us some excellent and telling examples in her deeplymoving book, Heartsounds, that chronicles the final four years of life of her physician-husband who goes through eight operations and eleven hospitalizations during that period. Together they identify the "it's your fault ploy" which means that no matter what goes wrong in the hospital setting, it is the fault of the patient, not the health care system:

Why did the operation take so long?

Because you lost so much blood.

Not: Because the surgeon blew it.

Why do you keep making these tests?

Because you have a very stubborn infection.

Not: Because I can't diagnose your case.

Why did I get sick again?

Because you were very weak. Not: Because I did not treat you competently the first time. ${ }^{18}$

Dr. Lear is constantly asking himself if he treated patients that way, and usually admits that he did. He suggests that every physician be required to spend at least a week per year in a hospital bed: "That would change some things in a hurry." 


\section{An Agenda for the 80's}

Since patients do have rights and do want to exercise them, and since the major attacks on the notion of patients' rights have been based on sloppy studies and false premises, the patients' rights movement is likely to gain momentum. Indeed, the 1970 s can be most properly viewed as a decade in which the existence of patients' rights became legitimized through basic education of the health care providers. I suggest that the 1980 s will be a decade in which the primary thrust will be working on ways to directly enhance the status of patients in the hospital as a means of humanizing the hospital environment so that patients can have a greater voice in how they are treated.

I suggest the following five point "agenda for the '80s:"

\section{Patients' Rights Agenda}

1. No Routine Procedures

2. Open Access to Medical Records

3. Twenty-Four-Hour-a-Day Visitor Rights

4. Full Experience Disclosure

5. Effective Patient Advocate

1. No Routine Procedures: It is all too common for nurses and others to respond to the question, "Why is this being done?" with, "Don't worry, it's routine." This should not be an acceptable response. No procedure should ever be performed on a patient because it is routine; it should only be performed if it is specifically indicated for that patient. Thus routine admission tests, routine use of johnnies, rou tine use of wheelchairs for in-hospital transportation, routine use of sleeping pills, to name a few notable examples, should be abolished. Use of these procedures means patients are treated as fungible robots rather than as individual human beings. Moreover, these procedures are often demeaning and unnecessary.

2. Open Access to Medical Records: While currently provided for by federal law and many state statutes and regulations, open access to medical records by patients remains difficult, and a patient of ten asserts his right to see his record at the peril of being labeled "distrustful" or a "trouble maker." The information in the hospital chart is about the patient and properly belongs to the patient. The patient must have access to it, both to enhance his own decision-making ability and to make it clear that the hospital is an "open" institution that is not trying to hide things from the patient. Surely if hospital personnel make decisions about the patient on the basis of information in the chart, the patient also deserves access to the information.

3. Twenty-Four-Hour-a-Day Visitor Rights: One of the most important ways both to humanize the hospital and to enhance patient autonomy is to assure the patient that at least one person of his choice has unlimited access to him or her at any time of the day or night. This person should also be permitted to stay with the patient during any procedure (e.g., childbirth or induction of anesthesia) so long as the person does not interfere with the care of other patients.

4. Full Experience Disclosure: The most important gain of the past decade has been the almost universal acknowledgement of the need for the patient's informed consent.

Nevertheless, some information that is material to the patient's decision is still withheld: the experience of the person doing the procedure. ${ }^{19} \mathrm{~Pa}$ tients have a right to know if the person asking permission to draw blood, take blood gases, do a bone marrow aspiration, or do a spinal tap has ever performed the procedure before, and if so, what the person's complication rate is. This applies not only to medical students and student nurses, but also to board certified surgeons - we all do things for the first time, and not every patient wants to take such an active role in our education.

\section{An Effective Patient Advocate:} While a patients' bill of rights is necessary, it is not sufficient. Rights are not self-actualizing. Patients are sick and desire relief from pain and discomfort more than they demonstrate a desire to exercise their rights; they are also anxious, and may hold back complaints for fear of retaliation. It is critical that patients have access to a person whose job it is to work for the patient to help the patient exercise the rights outlined in the institution's bill of rights. This person should sit in on all major hospital committees that deal with patient care, have authority to obtain medical records for patients, call consultants, launch complaints directly with all members of the hospital, medical, nursing, and administrative staff, and be able to delay discharges. While there appear to be some successful "patient representatives" that are hired by the hospitals, it is not fair to give them this title since they must represent their employer - the hospital. It is likely that ultimately effective representation can only be obtained by someone who is hired by a consumer group or governmental agency outside the hospital in which the representative works.

\section{Conclusion}

We have made a beginning in the long journey toward humanizing the hospital and promoting patients' self-determination. But more specific measures are needed before patients will be assured that they can effectively exercise their rights in institutional settings.

Like Poe's Arthur Gordon Pym, the notion that patients have rights has survived the days of darkness, isolation, and starvation. Patients' rights are now generally accepted (although sporadically attacked) and it is up to patients and providers alike to see to it that these rights become a reality for every citizen.

\section{References}

1. Rabkin, M., quoted in Annas, G.J.. The Hospiral: A Patient Rights Wasteland, CIVIL LIB. ERTIES REVIEW (Fall 1974) at 11

2. See generally G.J. ANNAS, The RIGHTSOF HoSPITAL PATIENTS (Avon Books, New York) (1975).

3. Margolis, E.G. Conceprual Aspects of a Pa tient's Bill of Rights, CONNECTICUT MEDICINE SUPPLEMENT 43:9 (Otrober 1979). See also Ladd. Legalism and Medical Erhics, in DAVIS, HOFF. MASTER, SHORTEN, eds., CONTEMPORARY IS SUES IN BIOMEDICAL ETHICS (Humana Press, New Jersey) (1978).

4. Examples of patient abuse based on pro viders' misunderstanding of the law after the Sajkeu'icz case in Massachusetts are cited in Annas, G.]., Reconciling Quinlan and Saikewicz: Decision Making for the Terminally Ill Incompetent, AMERICAN JOURNAL OF LAw \& MEDICINE 4(4):367, 387 (Winter 1979).

5. J. RAWLS, A THEORY OF JUSTICE (Harvard Univ. Press, Cambridge, Mass.) (1971)

Continued on page 46 
rences in Intensive Care Units, SCALPEL. A.:DQCILL 15(3): 1 -12 (October 1981) [10-095].

Methicillin-Resistant Staphylococcus aureus - United States, MORBIDITY AND MORTALITY WEEKLY REPORT 30(45): $557-59$ (November 20, 1981) [10-032].

- Retrolental Fibroplasia: A Mod. ER: PARABle. By William A. Silverman, M.D. (Grune \& Stratton, 111 Fifth Ave., New York, NY 10003) (1980) 246 pp., \$23.50.

\section{b) Pain and Suffering}

de Marneffe BR, The Inhumanity of Pain, JOLRNAL OF DRLG lsSUES 11(4): 415-22 (Fall 1981) [10-071].

\section{Medical Records}

Manual on Medical Records in Massachusetts Health Care Facilities, prepared by Massachusetts Medical Records Association (1981) [10-099].

\section{Medical Self-Care}

- How to be Yolr OWN DOCTORSOMETIMES. By Keith W. Sehnert, M.D. with Howard Eisenberg (Grosset $\&$ Dunlap, P.O. Box 857, Madison Square Station, New York, NY 10159) (1981) 341 pp., $\$ 7.95$ (paper).

\section{Medicine for Attorneys}

Kapp MB, Medical Books as Evidence: An Attomey's Introduction to the Literature, Florida BAR JOL'RNal, pp. 795 98 (December 1981) [10-106].

LANe Medical Litigation Guide. Edited by Fred Lane, J.D., David A. Birnbaum, M.D., and Alan Craig Hoffman, J.D. (Callaghan \& Co., 165 N. Archer Ave., Mundele in, IL 60060) (1981) three volumes, looseleaf, $\$ 210.00$.

- Clinical Cardiology (3d edition) (Lange Medical Publications, Los Altos, Calif.) (1981) $\$ 21.50$.

Medicine and the Law: Six Hour Self. Study Aldiotape Cassette Program Prepared For SEMINAR HELD IN BOS. TON, OCtOBER 1981. By Massachusetts Continuing Law Institute (Publications, MCLE-NELI, 44 School St., Boston, MA 02108) (1981) \$42.00.
Mental Health $\&$ the Law

Fleischner RD, Brewster v. Dukakis: A Status Report, ADV'ISOR 3(2): 4-6 (November 1981) [10-098]

Zlotnick D, First Do No Harm: Least Restrictive Altemative Analysis and the Right of Mental Patients to Refuse Treatment, WEST VIRGINIA LAW REVIEW 83(3): 376-444 (Spring 1981).

Ethical Problems in the Legal Representation of the Mentally Handicapped, ADV1SOR 3(2): 1-4 (November 1981)

[10-097].

The Forcible Medication of Involuntarily Committed Mental Patients with Antipsychotic Drugs - Rogers v. Okin, Georgia Law Review 15(3): 739-62 (Spring 1981).
Note, State Mental Patients' Right to Re fuse Forcible Administration of Medica. tion Narrou'ly Construed. SETON HALL L.AW REIIEW' 11(4): 796-805 (1981).

Practice Manual: Preparation and Trial of a Civil Commitment Case (Part 3), MEnTAL Disability Laur RePorter 5(5): 358-73 (September/October 1981) [10-023].

Ethical Issles in Mental Health Pol. ICY AND ADMINISTRATION: CONFERENCE REPORT AND BIBLIOGRAPHY (U.S. Dept. of Health and Human Services, Alcohol, Drug Abuse, and Mental Health Administration, Rockville, Maryland) (1981) 48 pp. [10-093].

The Least Restrictive Alternative: Principles and Practices. By H. Ruth-
Patients' Rights - continued from page 35

6. R. DWORKIN, TAKING KIGHTS SERIOUSLY (Harvard Univ. Press, Cambridge, Mass.) (1977).

7. Id. at 205.

8. Reprinted in Annas, supra note 1, at 25 27 .

9. Altman, J.H., et al., Patients Who See Their Medical Record, New ENGLAND Journal of MEDICINE 302(3):169 (January 17, 1980).

10. Lipsett, D.. Editorial, NEW ENGLAND JOURNAL OF MEDICINE 302(3):167 (January 17 1980)

11 R. BL'RT. TAKING Care of Strangers: THE RLle of LAW' IN DOCTOR-PATIENT Rela. TIONS (Free Press. New York) (1979) at 43. 12. Stewns, D.P., Stagg, R., MacKay, I., W'hat Happens W'hen Hospitalized Patien is See Their Oun Records, ANNALS Of INTERNal MED CINE 86:474,476 (1977). For a more com plete discussion of this issue, including additional studies of patients given routine access to their records, see G.]. AN'NAS, L.H. GLANTZ, B.F.

Katz, The RightS OF DOCTORS, NuRSES AND Allied Healty Professionals (Avon Books, New York) (1981) at 159-61.

13. Golodetz, A., Ruess, J., Milhous, R., The Right to Know: Giving the Patient His Medical Rec ord. ARCHIVES OF PHYSICAL MEDICINE AND RE. HABILITATION 57:78, 80 (1976). Experience un der the new record access regulation enacted by the Massachusetts Board of Registration in Medicine indicates that patients want access to their records for a variety of reasons. In the period from October 13, 1978 (when the regulation went into effect) to January 31، 1980, the Board received more phone calls from consumers asking about the medical records regu lation (approximately ten per month) than about any other single issue dealt with by the Board. There were also 33 formal complaints filed concerning record access during this pe. riod. Of this number, almost half (16) needed help from the Board to get their physician to forward a copy of their records directly to another physician. Of the remaining 17, six needed information for insurance purposes, six wanted to personally review the records for various reasons, one alleged negligence, one wanted the record sent to a school nurse, one was moving to another state, one wanted a sec ond opinion, and one wanted her contact lens prescription. (Statistics compiled by Judy Miller, a student at Boston College Law School.)

14. See. e.g., Laforet, E.G., The Ficion of $i n-$ formed Consent. JOLRNAL OF THE AMERICAN MEDICAL AsSOClatio: 235:1579 (April 1? 1976).

15. Cassileth, B.R., et al., Informed ConsentW'hy Ate its Goals Imperfectly Realized? NEW ENGLAND JOURNAL OF MEDICINE 302(16):396 (April 17, 1980).

16. See generally chapter on Informed Consent in G.J. ANNAS, L.H. GLANTZ, B.F. KaTZ, THE Rights Of DOCTORS, NuRSES AND AlLiED Health PRofessionals (Avon Books, New York) (1981): and G.J. ANNAS, L.H. GLANTZ. B.F. KATZ, INFORMED CONSENT TO HLMAN EX. perimentation: The Subjects Dilemma (Bal. linger, Ca mbridge, Mass.) (1977). See also Rennie, D. Informed Consent by "Well-.Vigh Abject" Adules. NEW ENGLAND JOURNAL OF MEDICINE 302(16):916 (April 17, 1980). "I suggest that the physician accept far more than simply the duty to improve consent forms. . . . They should accept education of the patient through the process of consent as a worthwhile thera. peutic goal. To deny the possibility of informed consent is to ensure that it will never be achieved - an atcitude that is immoral and ... illegal." Id. at 918.

17. Thomas, L. On Magic in Medicine. NEW EnGlaNd Journal of Medicine 299:461, 462 (August 31, 1978).

18. M.L. Le.AR, HeARTSOLNDS (Simon \& Schuster, New York) (1980) at 47.

19. Annas, G.J., The Care of Pric'ate Patients in Teaching Hospitals: Legal Implications, BL'LLE. TIN OF NEW YORK ACADEMY OF MEDICINE 56(4):403-11 (May 1980). 